\title{
Modeling the Pressure Distribution and the Changes of Water Level around the Offshore Platforms Exposed to Waves, Using the Numerical Model of Flow 3D
}

\author{
Milad Rashidinasab', Mehdi Behdarvandi Askar2* \\ ${ }^{1}$ Khorramshahr University of Marine Science and Technology, Khorramshahr, Iran \\ ${ }^{2}$ Department of Offshore Structures, Faculty of Marine Engineering, Khorramshahr University of Marine Science and Technology, \\ Khorramshahr, Iran
}

Email: *sazehenteghal@yahoo.com

How to cite this paper: Rashidinasab, M. and Askar, M.B. (2017) Modeling the Pressure Distribution and the Changes of Water Level around the Offshore Platforms Exposed to Waves, Using the Numerical Model of Flow 3D. Computational Water, Energy, and Environmental Engineering, 6, 97-106. http://dx.doi.org/10.4236/cweee.2017.61008

Received: November 24, 2016

Accepted: January 8, 2017

Published: January 11, 2017

Copyright (c) 2017 by authors and Scientific Research Publishing Inc. This work is licensed under the Creative Commons Attribution International License (CC BY 4.0).

http://creativecommons.org/licenses/by/4.0/

\begin{abstract}
The humans' need to use the oceans for exploration and extraction of oil has led to the development of engineering science in the field of offshore structures. Since it's important to examine the offshore structures from different aspects and perspectives, we would have to evaluate many different parameters about them. So categorizing these parameters can help to perform their related analysis with more accuracy and more details. Due to the efficient force it exerts on the structure, the pressure distribution around every marine or hydraulic structure has a significant importance, and it even accounts for one of the dominant issues in designing and building of such structures. In the present study, an oil platform located in Phase 15 of South Pars oil fields, located in the Persian Gulf waters, has been analyzed using the FLOW 3D software. The outputs indicate that the pressure of water is distributed almost hydrostatically with the depth, and its maximum reaches $0.6 \mathrm{MPa}$ at the bottom.
\end{abstract}

\section{Keywords}

Pressure Distribution, Offshore Platforms, Changes of Water Level, Modeling

\section{Introduction}

From 1956, for taking into account the objectives of economic and optimizing aspects, the platforms' decks began to decrease in scale, and a new generation of platforms similar to the ones today was built and developed. Also, the use of the sloped foundations beneath the structures and some provisions for the constructing podium in depth and at further points were began in those years, and now the tallest casted platform has been placed at a depth of 315.5 meters in the Gulf of Mexico [1]. The extraction of oil 
from the marine resources is often performed through the platforms and offshore constructions. In 1988, oil production by offshore platforms had a $9 \%$ the share of the global consumption, and in 2000 this share was equal to $24 \%$. These numbers indicate the increasing growth of the share of offshore platforms in production of oil and gas. If we remember that these huge structures are necessarily built on land and then transported and installed at sea through complex operations, then we can reach a wide understanding of the vast engineering knowledge that is required to design and construct them. It's hoped that this paper results in taking a small step forward in the development of technical information about the field of offshore platforms. In 1987, Allender and Petrauskas conducted a series of experiments on a scaled structure, in which, the uniform flow was simulated by moving the model inside stationary water. During those experiments, about the regular waves, it was observed that in the absence of uniform flow, the anticipated forces are higher than the measured ones, while in the presence of the uniform flows along with the regular waves, those anticipated forces would be smaller than the measured values. In the case of random waves, the maximum measured forces in both cases were about 10 to 20 percent less than those measured for regular waves at the same depth under the same uniform flow [2]. In 1992, Heidman and Weaver made a comparison between the predicted and measured forces on the components of three offshore platforms. Their experiments are done on real platforms and considering empirical corrections, such as the kinematic coefficient caused by the three-dimensional nature of the propagation of wave in the sea, the blockage coefficient of the uniform flow, the loading coefficients of the side components and the well guides. After studying 458 cases of single waves, they concluded that the forces expected through the consideration of API Code, are approximately 5\% smaller than the measured forces [3]. In 1993, a series of large scale experiments were carried out in the delta wave channel of Delft Hydraulics Laboratory, in the Netherlands. The purpose of these tests was to determine the forces exerted by the waves and the sea currents on the cylindrical legs of offshore structures [4]. Yougang Tang's studies in 2015 are based on the goal of developing a warning system for the times of severe displacements having values outside the defined range. In those studies the warning conditions were defined having three levels. And these conditions has been introduced according to the applied stresses and any movement of the platforms' jacket. The feasibility of this study has been conducted in a platform jacket in South China Sea [5]. In the year 1390, Hedayatifar and Mazaheri made a study as the pushover analysis of offshore platforms under the wave impact forces to the deck. The impact forces on marine structures are 2 to 4 times larger than the non-impact forces having the same domain. Also, the impact pressure may be 10 times larger than the non-impact pressure. The duration of these impact forces is very low and it's usually 2 to 4 seconds. One of the points that the API Regulations emphasize on them for conducting the pushover analysis, is the case where the deck height is insufficient and so, the waves hit the deck. These wave forces on the deck were one of the main causes of damage to platforms in the Gulf of Mexico and the North Sea, and so the platforms under these forces essentially require inspections and investigations. In this research, we first study a fixed offshore platform located inside the Persian Gulf, based on the static and pushover analysis, and then we determine 
whether or not the platform has the ability to stand wave forces applied to the deck. This task is performed by modeling and the analysis done in SACS software. In the figure below, the effects of different hydrodynamic parameters of the waves on the leg shear of offshore platforms are illustrated [6].

\section{The Materials and Methods}

Generally, the steel jackets can be considered as structures having simple hydrodynamics. Thus, the resulting force of the waves on those components of the structure in the water, can be calculated using the Morrison equation as a set of the inertial force (proportional to the acceleration of the water particles) and the non-linear drag force (proportional to the square of the speed of the water particles):

$$
F=C_{M} \frac{\rho \pi D^{2}}{4} v+C_{D} \frac{\rho D}{2} v|v|
$$

In this equation, $F$ is the wave force per unit length of cylinder, expressed in Newton, $v$ and $|v|$ are respectively the real value and the absolute value of the velocity of water particles along the axis perpendicular to the cylinder, determined by applying the wave theory along the cylinder axis, and are expressed by the unit of meters per second. Also, $\rho$ represents the Water density in $\mathrm{kg} / \mathrm{m}^{3}, D$ is the cylinder's diameter in meters and after considering the marine plants, $C_{D}$ is the drag coefficient and $C_{M}$ is the inertia coefficient. This form of the Morrison equation is valid for a fixed cylindrical. For analyzing the motion efficiency of a structure, the above equation must be modified so that its movements of the cylinder are considered too [7]. The coefficients $C_{D}$ and $C_{M}$ depend to the roughness of cylindrical surface, the applied wave theory and other parameters of the flow. According to the API-RP2A criteria, the equivalent value of $C_{D}$ is between 0.6 and $1 / 2$, and for $C_{M}$ it is between 1.3 and 2. Further information about this can be obtained from the DNV regulations [8]. The total amount of the wave forces exerted on each member is obtained by numerical integration along its length. The fluid's velocity and acceleration in integration points are calculated directly using the selected wave theory.

According to the Morrison equation, the drag force would be non-linear. In the wave method this equation is used as nonlinear. However, in order to determine the transmission function needed in calculations of the frequency-domain method, a good linear definition must be obtained for the drag forces [9]. Therefore, the frequency domain analysis may be more appropriate for calculating the fatigue life of the structure, because in this situation, the resultant forces acting on the operational floors of the structure by the normal waves are caused by the inertia forces which are often linear. In the dynamic analysis of structures located in deep waters and exposed to big storm waves, the non-linear drag forces make up for the main part of the forces of waves. Therefore, the analysis of these structures must be performed as non-linear and inside the time-domain.

The start of FLOW-3D numerical model dates back to 1963, when in the Los Alamos (LANL) laboratory, Doctor C.W. Tony Hirtproposed a unique method named VOF (Volune of Fluid), to increase the robustness of numerical methods. His job at the time, was to create and develop a method for modeling fluid dynamics for scientific and industrial applications. Accordingly, to expand and improve his work, he chose ap- 
proaches like using the feedbacks obtained from the industrial and computing units for creating a CFD (Computational Fluid Dynamics) software. In 1985, this process resulted in building a high-performance software called FLOW-3D. Now by upgrading the software, after years, FLOW-3D, has remained a comprehensive computational fluid dynamics software for commercial, scientific, military and industrial purposes [10]. The governing equations in this model-as in other similar models-are the Navier-Stokes equations and the equation of mass conservation. For modeling a channel in this software, we first need to define the general properties (including simulation time and the system of units), physical conditions, the geometry and the model analyzing system and the adjustment of outputs and its related options. In this study, the metric system of units is applied and the unit of Celsius degrees was chosen for temperature. In the panel of physical properties in the soft ware, it allows us to adjust the conditions, according to the governing physical principles of the related phenomena. The governing physical conditions in this study include viscosity, gravity force and turbulence. In this software, the turbulence can be simulated through five models, and the model of normalized groups (RNG) is the model used for this study [11].

Since the Persian Gulf waves are more similar to the JONSWAP waves, we have used the JONSWAP table for the extraction of the wave spectrum. According to the studies of Mazaheri and Ghaderiin 2011, JONSWAP waves have the nearest wave pattern to the waves of the Persian Gulf. So in this study, the pattern of the waves hitting the offshore platform's structure has been selected accordingly [12].

So, taking into account $U_{10}(\mathrm{~m} / \mathrm{s})$ as the wind speed, $F(\mathrm{~m})$ as the field length, and $\gamma$ as the shape parameter, the spectral density $S(f)$ would be defined as follows [13]:

$$
\begin{gathered}
S(f)=\frac{a g^{2}}{(2 \pi)^{4} f^{5}} \exp \left[-1.25\left(\frac{f}{f_{p}}\right)^{-4}\right]^{\exp \left[\frac{\left(\frac{f}{f_{p}}-1\right)^{2}}{2 \sigma^{2}}\right]} \\
f_{p}=3.5\left[\frac{g^{2} F}{U_{10}^{3}}\right]^{-0.33} \\
1 \leq \gamma \leq 7, \text { Default } 3.3 \\
f \leq f_{p} \Rightarrow \sigma=0.07 \\
f>f_{p} \Rightarrow \sigma=0.09
\end{gathered}
$$

This research investigates the change of the velocity on seawall crown by considering the obstacles in different layouts and slopes [14]. The intended slopes for seawalls were $22,27,32,39$ degrees, respectively and had the roughness heights on wall surface were $15 \mathrm{~cm}, 20 \mathrm{~cm}$ and $30 \mathrm{~cm}$. Moreover, four types of roughness layouts on the wall surface were investigated [15]. A wide range of studies have been conducted in aforementioned parameters is followed by the complexity connection with symmetrical compound rectangular of the hydraulic flow. Such differences cause an channels and the investigation of the apparent shear interaction between deep flow in the main channel and stress in them as well as the effect of various parameters [16]. Breakwaters are structures which are constructed in order to create peace in a pool of ports, to prevent port erosion, and to protect the shipping channel [17]. 
Generally, the geometric properties of different floors of the platform's structure, are as follows. As examples, the three-dimensional geometric forms, plans, and the views of A and 1 cross sections, are shown in below (Figures 1-4). The original height selected

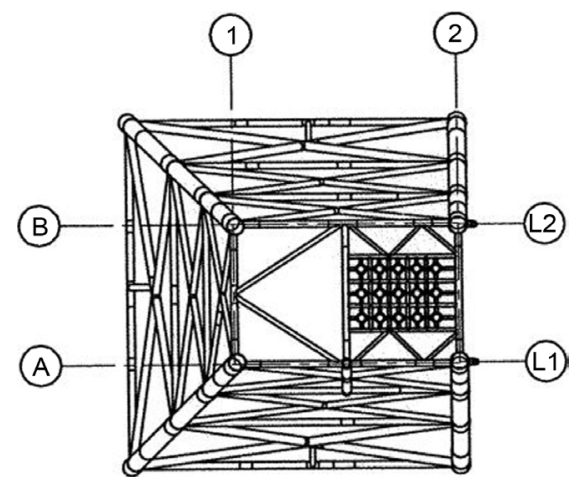

Figure 1. Three-dimensional shape and plan of the offshore platform (SPD 15) in phase 15 of South Pars oil field.

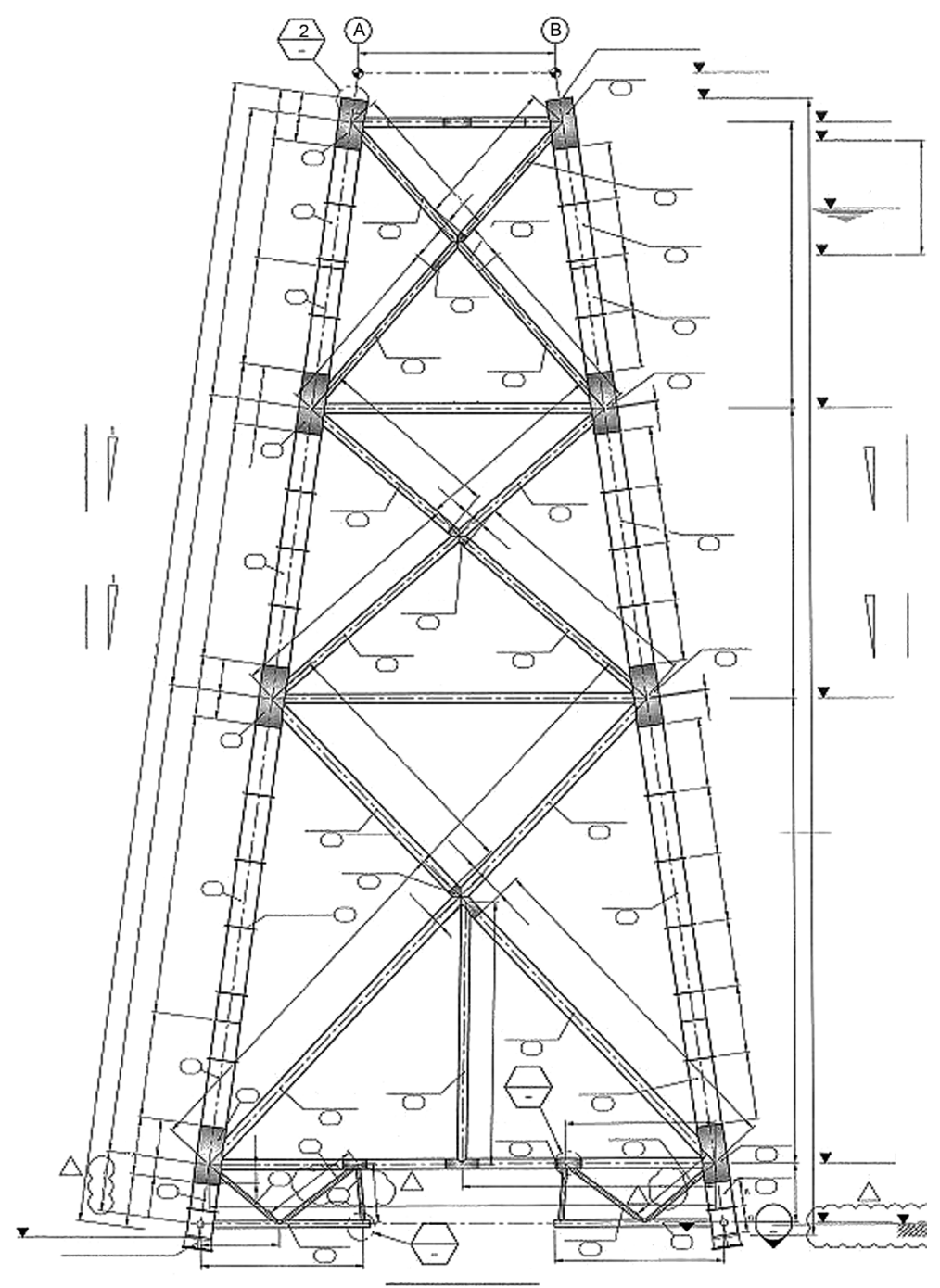

Figure 2. The cross section A of offshore platform (SPD 15) in phase 15 of South Pars oil field. 


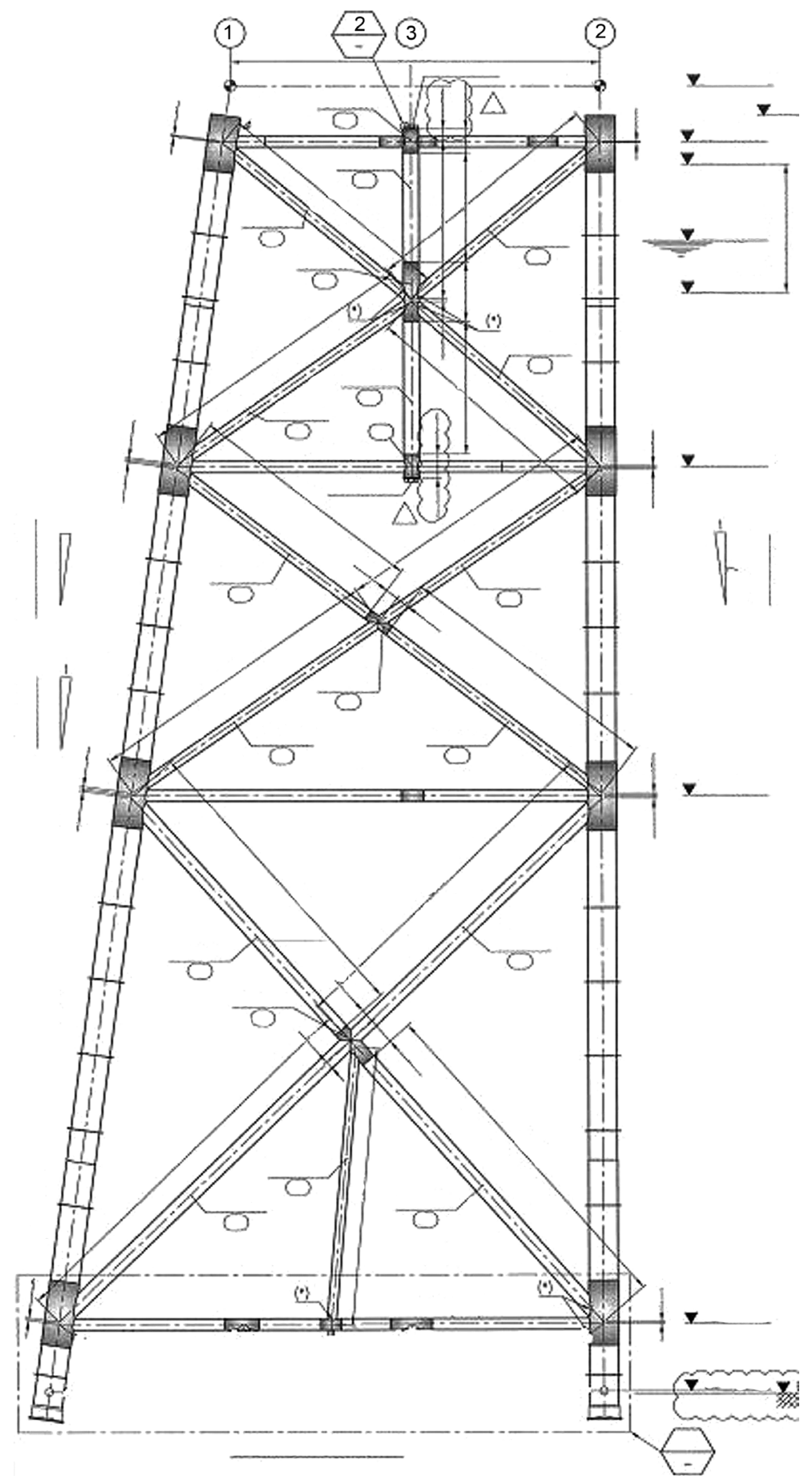

Figure 3. The cross section 1 of offshore platform (SPD 15) in phase 15 of South Pars oil field.

for the platform's legs is equal to 75.6 meters, installed at a depth of 66.6 meters beneath the water.

\section{Conclusions}

After applying the geometric conditions, hydrodynamic conditions and the structural conditions of the offshore platform, on the numerical model, and running the program, the below results were obtained for the three-dimensional simulation: 
As it can be seen in Figure 5, the pressure of water is distributed almost hydrostatically with the depth, and its maximum reaches $0.6 \mathrm{MPa}$ at the bottom. It's necessary to mention here that the depth hydrostatic pressure of the flow for the other directions is also similar to the diagram above. In Figure 6 and Figure 7, the pressure changes in the transverse direction near the bottom and close to the offshore platform structure are shown as two-dimensional and one-dimensional views. As it can be seen in Figure 6, the lowest amount of pressure in the transverse direction as for the longitudinal direction would occur on the surface, and its number might even become negative.

As can be seen in Figure 7, since the water depth is almost identical for the transverse direction, the pressure distribution in the transverse direction is also a line, which indicates the hydrostatic pressure of $6.0 \mathrm{MPa}$ for the transverse direction. According to Figure 4 and Figure 6, we can conclude that the pressure distribution around the offshore platform under consideration is close to the hydrostatic pressure and almost equal to it, except that the hydraulic pressure decreases more rapidly in the traverse direction.

Figure 8 shows how the free surface of water changes as the waves hit the offshore

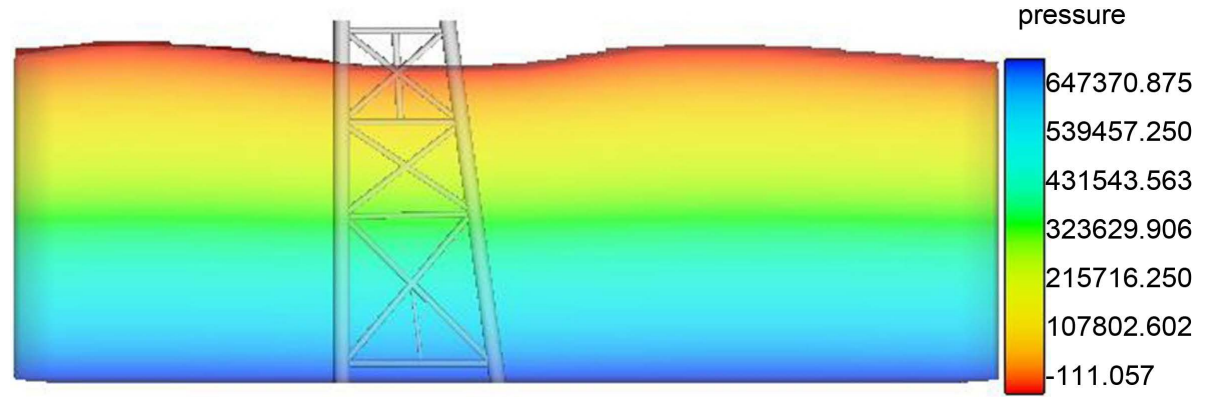

Figure 4. The hydrostatic fluid pressure distribution of the numerical model of Flow 3D, in longitudinal direction.

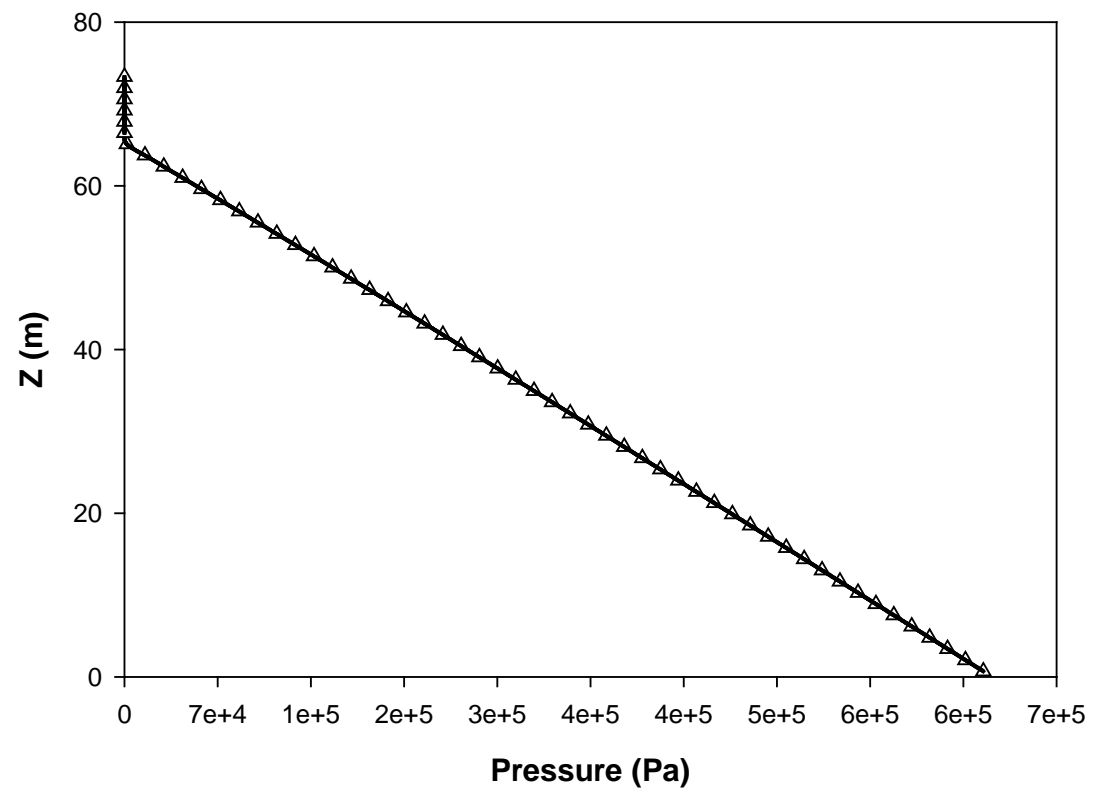

Figure 5. The changes of water pressure in the depth direction of the flow around the offshore platform structure. 


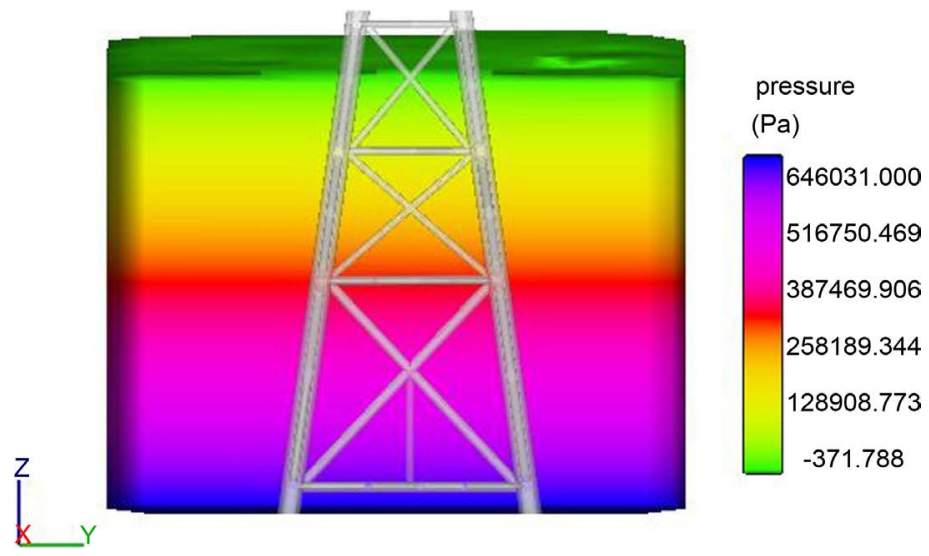

Figure 6. The hydrostatic pressure distribution of the fluid in the transverse direction, by the Flow 3D numerical model.

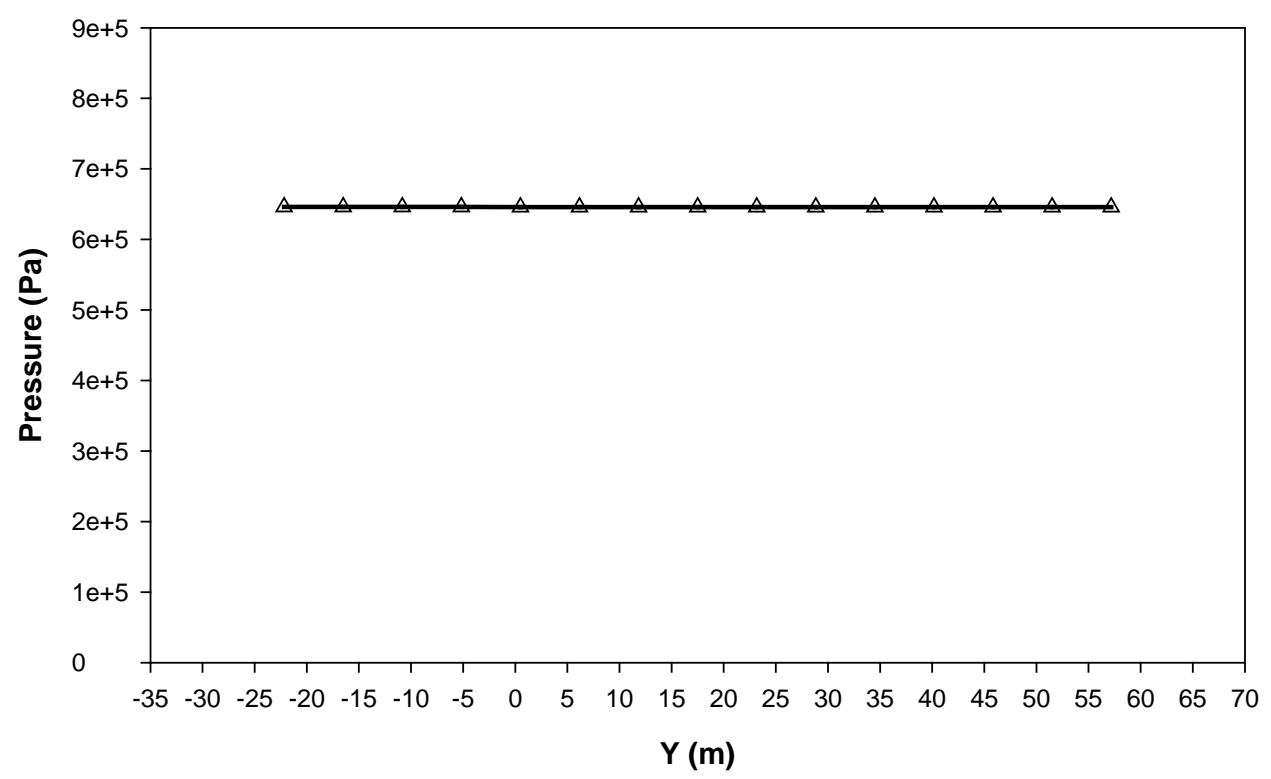

Figure 7. The distribution of water pressure in the transverse direction close to the offshore platform structure.

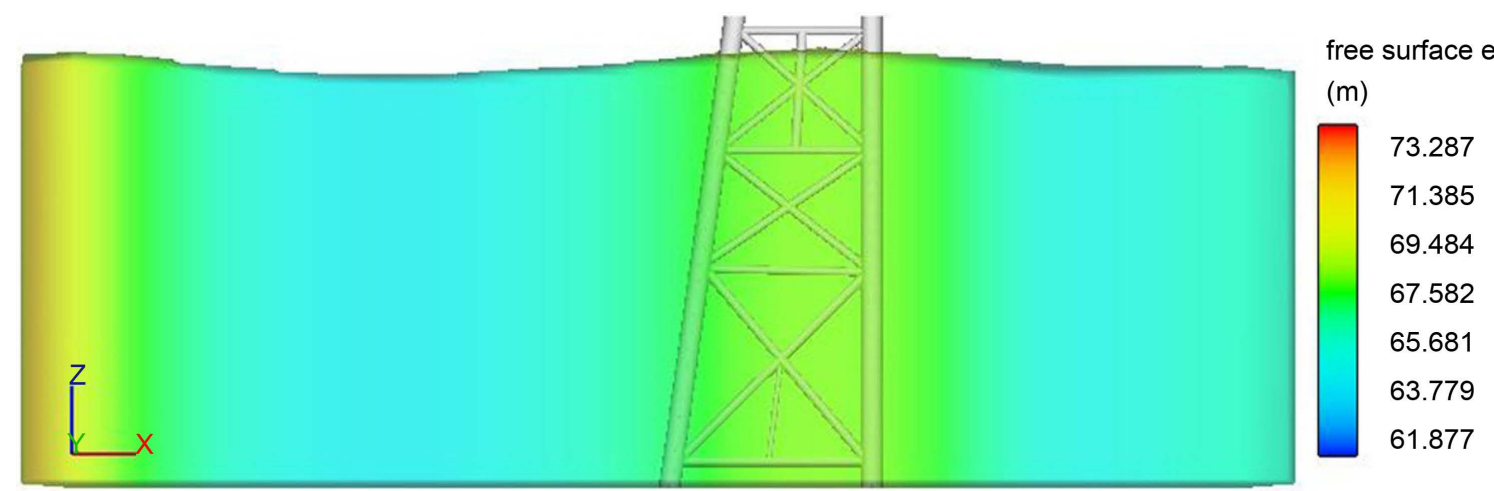

Figure 8. The changes of the free surface of the waves that hit an offshore platform in Persian Gulf.

platforms. According to this figure, the most changes and fluctuations of the water level occur at the very same place the waves touch the structure, so that there are more se- 
vere changes at this location than the places after or before it. The lowest water level is 61.78 meters and its maximum number reaches 73.28 meters.

\section{References}

[1] Allender, J.H. and Petrauskas, C. (1987) Measured and Predicted Wave plus Current Loading on a Laboratory Scale Space Frame Structure. Proceedings of 19th Annual Offshore Technology Conference, Houston, 27-30 April 1987, Vol. 1, 143-151.

[2] Anagnostopoulos, S.A. (1982) Dynamic Response of Offshore Structures to Extreme Waves including Fluid-Structure Interaction. Engineering Structures, 4, 179-185. https://doi.org/10.1016/0141-0296(82)90007-4

[3] Heidman, J.C. and Weaver, T.O. (1992) Static Wave Loading Procedure for Platform Design. Civil Engineering in the Oceans V, 496-519.

[4] Mackwood, P.R. (1993) Wave and Current Flows around Circular Cylinders at Large Scale. LIP Project 10D, 27.

[5] Tang, Y.G., et al. (2015) Study on the Structural Monitoring and Early Warning Conditions of Aging Jacket Platforms. Ocean Engineering, 101, 152-160.

https://doi.org/10.1016/j.oceaneng.2015.04.011

[6] Hedayatifar and Mazaheri (2011) The Pushover Analysis of Offshore Structures Exposed to Impact Forces of the Waves on the Deck. The Fifth Iranian Hydraulic Conference.

[7] Mazaheri, S. and Ghaderi, Z. (2011) Shallow Water Wave Characteristics in Persian Gulf. Journal of Coastal Research, Special Issue, 64, 572-575.

[8] Deilami-Tarifi, M.A., Behdarvandi-Askar, M.E., Chegini, V. and Haghighi-Pour, S.A. (2015) Effect of Slope, Size, and Arrangement of Roughness of Sea Wall on Overtopping of Random Waves. International Journal of Biology, Pharmacy and Applied Sciences, 4, 10261034.

[9] Tabeshpour, M.R., Golafshani, A.A. and Seif, M.S. (2006) Comprehensive Study on the Results of the TLP Responses in Random Sea. JZUS.

[10] Bahadori, S. and Askar, M. (2016) Investigating the Effect of Relative Width on Momentum Transfer between Main Channel and Floodplain in Rough Rectangular Compound Channel Sunder Varius Relative Depth Condition. Open Journal of Geology, 6, 225-231. https://doi.org/10.4236/ojg.2016.64020

[11] Carter, D.J.T. (1982) Prediction of Wave Height and Period for a Constant Wind Velocity Using the JONSWAP Results. Ocean Engineering, 9, 17-33. https://doi.org/10.1016/0029-8018(82)90042-7

[12] Askar, M.B. and Moghadam, M.F. (2013) Momentum Attraction by Flood Plains in Compound Channel. Journal of Engineering and Technology, 2, 7-15.

[13] Moghadam, M.F. and Aska, M.B. (2014) Studying Momentum Transfer between the SubSections of a Symmetric Compound Rectangular Section Using Forcmeasurment Method. Indian Journal of Scientific Research, 4, 248-257.

[14] Deilami-Tarifi, M., Behdarvandi-Askar, M., Chegini, V. and Haghighi-Pour, S. (2016) Modeling of the Changes in Flow Velocity on Seawalls under Different Conditions Using FLOW-3D Software. Open Journal of Marine Science, 6, 317-322. https://doi.org/10.4236/ojms.2016.62026

[15] Ebrahimi, A., Askar, M.B., Pour, S.H. and Chegini, V. (2015) Investigation of Various Random Wave Run-Up Amounts under the Influence of Different Slopes and Roughnesses. Environment Conservation Journal, 16, 301-308.

[16] Bahadori, S. and Askar, M.B. (2016) Investigating the Effect of Latitudinal Slope of Floodplain and Relative Roughness on Apparent Shear Stress in Symmetric Compound Rectan- 
gular Channels with Varius Relative Width. Journal of Engineering and Applied Sciences, $11,57-62$.

[17] Mifoor, I., Askar, M.B. and Pour, S.H. (2016) On the Investigation of Basic Parameters of Designing Protective Layer of the Offshore Breakwaters at Iran's Kharg Island. International Journal of Recent Scientific Research, 7, 9821-9823.

Submit or recommend next manuscript to SCIRP and we will provide best service for you:

Accepting pre-submission inquiries through Email, Facebook, LinkedIn, Twitter, etc. A wide selection of journals (inclusive of 9 subjects, more than 200 journals) Providing 24-hour high-quality service User-friendly online submission system Fair and swift peer-review system Efficient typesetting and proofreading procedure Display of the result of downloads and visits, as well as the number of cited articles Maximum dissemination of your research work

Submit your manuscript at: http://papersubmission.scirp.org/ Or contact cweee@scirp.org 